\title{
Telling stories
}

\section{Bryan Silcock}

Presenting Science to the Public. By Barbara Gastel.

ISI Press, Philadelphia: 1983. Pp.146. Hbk $\$ 17.95$ (North America),

$\$ 20.95$ (elsewhere); pbk \$11.95 (North America), $\$ 14.95$ (elsewhere).

JUST over 30 years ago Nature published a report of what is now recognized as one of the key discoveries of modern biology.Like most scientific papers it was written in a kind of code. Who outside the small group then interested in DNA could have recognized the significance of Watson and Crick's structure from their letter alone? The only hint that it was anything out of the ordinary was the throwaway line "It has not escaped our notice that the specific pairing we have postulated immediately suggests a possible copying mechanism for the genetic material", and this was intended not to inform but to establish a claim.

Yet the structure of DNA was clearly of immense general interest. It answered a fundamental question about life that occurs to anyone with a little intellectual curiosity, and, as we now know, it had farreaching implications for medicine and technology. In 1953 they could not be foreseen in detail, but genetic manipulation was obviously among them.

The formal methods of scientific communication are, in fact, of little use to people who want a broad view of what is going on in science: scientists interested in disciplines other than their own; politicians who vote funds for research; taxpayers who provide them. Science does need to be presented to the public. Barbara Gastel, who teaches science journalism at the Massachusetts Institute of Technology, takes most of this for granted. Her book is very much a practical manual, for the working scientist wishing to try his hand at a bit of popularization and for his colleague who willy-nilly becomes the object of media attention. Nearly half of it is concerned with presenting science through the mass media.

The advice offered is well informed, sensible and concise, though the occasional passage such as "the main item that succeeds interaction with a journalist is likely to be a story" does seem to have diffused into the main text from some list of things writers should not do. However, as a participant in many such interactions I can vouch for her understanding of the problems. Any scientist unfamiliar with the workings of the media will find the book useful.

It is said to be a good working rule that relations between journalists and politicians should be bad. I do not believe the same rule applies to journalists and scientists, but it must be admitted that relations are often strained. Why is there so much friction? Leaving aside the occasions on which reporters simply get things wrong, it does seem from where I stand, on the media side of the fence, that those on the other side must take some of the blame for a lot of unnecessary misunderstanding. Many scientists seem to regard a press report on their work as a kind of debased research paper. It is of course nothing of the kind. As the example of DNA shows, the scientific paper is a very formalized mode of communication; it makes no attempt to put the work described in any kind of broad

\section{IMAGE UNAVAILABLE FOR COPYRIGHT REASONS}

\section{A SUPERJAB that will cure certain types of cancer will be available in Britain within a year. \\ The amazing breakthrough was revealed The amazing breakthrough was revealed
yesterday by pioneering British scientist Dr
Mikn Waterfielf}

Journalism at its worst - but do scientists appreciate the demands of the media?

perspective, and deliberately eschews extrapolation and speculation. Yet for the general public the first is essential, the second desirable and the third of ten useful. Governments fund research and taxpayers pay for it because they believe it will bring benefits. They are entitled to know both what is just around the corner and what is looming over the horizon.

The simplification that accompanies popularization is another common source of friction. Although nearly all scientists concede that complex ideas need to be simplified for a general audience, they are often unhappy with the results. Many of the things they object to are the unavoidable consequences of the simplification and compression essential in the popularization of science.

As Gastel says, a good working rule is never to underestimate people's intelligence and never to overestimate their knowledge. But consider the application of this rule to, say, a popular account of the recent discovery of the $\mathrm{W}$ and $\mathrm{Z}$ particles at CERN. The line such an account should take is clear enough: the particles were predicted by a theory that unifies two of the four forces in nature; the discovery of the
$\mathrm{W}$ and $\mathrm{Z}$ therefore shows that the theory is on the right lines. But most people do not know there are four natural forces, let alone what they are. They are probably pretty hazy about fundamental particles, atoms and nuclei. A newspaper or TV report cannot afford to have a didactic air if it is to command any attention, and in any case there is not the space for long explanations. So reporters are forced to resort to fudges, short cuts and minor inaccuracies; calling particle accelerators atom smashers, for example, because they think their readers probably have not heard of particle accelerators but that they might have heard of atom smashers.

Gastel's description of these and other problems should help to provide the understanding that leads to tolerance. It is unfortunate though that she has virtually nothing to say about the most important aspect of the presentation of science to the public today: the way the media handle issues such as nuclear energy and genetic engineering that are at once technically complex and politically or ethically sensitive. In the long run an inaccurate newspaper report about fundamental particles does not matter. What newspapers and television have to say about controversial issues does. For better or worse the media have played a major part in promoting the anti-nuclear movement, and a few years ago an alarmist British television programme about criteria for brain death led to a sharp fall in the supply of kidneys for transplant operations.

Media coverage of such issues is often appallingly bad. Perhaps this is partly because journalists like above all to see themselves as exposers of wrongs, and as the champions of lonely crusaders against the system. Such attitudes help to preserve democratic freedoms, but they are not conducive to the sober analysis of complex technical issues and statistical arguments. The facts can begin to seem part of the system. In defence, I can only point out that the balls so enthusiastically kept in play are nearly always first thrown onto the field by a member of the scientific community. This is true of even the daftest ideas. The warning that evil governments might perpetuate themselves by cloning millions of compliant citizens was, if I remember rightly, first issued by a very eminent biologist.

So what should a scientist do when he is dragged into a media debate over whose form and content he has no control? Gastel points out in another context the importance of being patient and of not being patronizing - she might also have mentioned that there is nothing that so arouses the suspicions of a journalist as the feeling that information is being withheld.

Bryan Silcock is science correspondent of the Sunday Times. 